\title{
Nodal metastasis in well-differentiated follicular carcinoma of the thyroid: Its incidence and clinical significance
}

\author{
MITSUYOSHI HIROKAWA ${ }^{1}$, YASUHIRO ITO ${ }^{2}$, SEIJI KUMA ${ }^{1}$, YUUKI TAKAMURA ${ }^{2}$, \\ AKIHIRO MIYA $^{2}$, KAORU KOBAYASHI ${ }^{2}$ and AKIRA MIYAUCHI ${ }^{2}$
}

Departments of ${ }^{1}$ Diagnostic Pathology and ${ }^{2}$ Surgery, Kuma Hospital, Kobe, Japan

Received March 29, 2010; Accepted July 19, 2010

DOI: 10.3892/ol_00000154

\begin{abstract}
The clinical significance of nodal metastasis in well-differentiated follicular carcinoma (WD-FC) of the thyroid remains a controversial issue. This study aimed to clarify clinical and pathological characteristics of WD-FC with nodal metastasis, based on the new WHO classification. We examined 249 WD-FC cases diagnosed between 1983 and 2004 in our hospital. Poorly differentiated follicular carcinoma was not included in this study. Of the 249 WD-FC cases, $9(3.6 \%)$ revealed nodal metastasis. The incidences of nodal metastasis in minimally invasive and widely invasive cases were 2.0 and $9.8 \%$, respectively. In four patients, nodal metastasis was detected in the ipsilateral lymph nodes during the initial surgery. A total of 6 patients presented with nodal metastasis 2-10 years after the initial operation, and 3 patients with bilateral and large nodal metastases were relatively young. No patients succumbed to the carcinoma. Primary lesions of WD-FC with nodal metastasis were microscopically conventional, and there were no findings predicting nodal metastasis. We hypothesized that the incidence of nodal metastasis in WD-FC, based on the new WHO classification, was lower compared with previous reports. Younger individuals may be at a higher risk of large bilateral nodal metastasis. The presence of nodal metastasis did not affect the long-term outcome of follicular carcinoma.
\end{abstract}

\section{Introduction}

Follicular carcinoma of the thyroid is a malignant tumor showing evidence of follicular cell differentiation and lacking the diagnostic nuclear features of papillary carcinoma (1). It is less common than papillary carcinoma, comprising 10 to $20 \%$ of all thyroid carcinomas (2). Follicular carcinomas metastasize to regional lymph nodes, but the incidence is

Correspondence to: Dr Mitsuyoshi Hirokawa, Department of Diagnostic Pathology, Kuma Hospital, 8-2-35 Shimoyamate-dori, Chuo-ku, Kobe 650-0011, Japan

E-mail: mhirokawa@kuma-h.or.jp

Key words: thyroid, follicular carcinoma, metastasis, lymph node undoubtedly lower than in papillary carcinoma. The incidence of the nodal metastasis in follicular carcinomas is variable and has been estimated to be from 4.7 up to $30.0 \%$ (3-8), while its clinical significance remains controversial. Hughes et al (9) reported that nodal metastasis increases the risk of recurrence, but there is no difference in survival. On the other hand, Segal et al (7) suggested that nodal metastasis has a significantly negative effect on survival. It is well known that follicular predominant papillary carcinomas or follicular variant papillary carcinomas with nodal metastasis are occasionally regarded as follicular carcinoma (10-12). Therefore, the controversy concerning nodal metastasis of follicular carcinoma may originate from differences in the disease entity or diagnostic criteria.

Until 2004, the entity of follicular carcinoma had included both well-differentiated follicular carcinoma (WD-FC) and poorly differentiated follicular carcinoma (PD-FC) (10). According to the current WHO classification (1), follicular carcinoma means only WD-FC, with PD-FC being included in poorly differentiated carcinoma. Therefore, the biological behavior of follicular carcinoma should be re-examined under the present classification. This study aimed to clarify the clinical significance and pathological characteristics of follicular carcinomas, i.e., well-differentiated type, with nodal metastasis.

\section{Patients and methods}

Patients. A total of 441 patients underwent surgery for follicular thyroid carcinoma between January 1983 and December 2004 in Kuma Hospital, Japan. All histologic sections were reviewed by one pathologist (M.H.). Of the 441 patients, 248 were confirmed to have conventional WD-FC, 198 were classified as minimally invasive and 50 were classified as widely invasive. PD-FC was diagnosed in 44 patients and oncocytic follicular carcinoma was diagnosed in 43 . The remaining cases showed adenomatous nodule, adenomatous goiter, follicular adenoma and papillary carcinoma, including a predominant follicular pattern and follicular variant. A total of 8 WD-FC cases revealed nodal metastasis; these cases were clinically and pathologically examined. Additionally, a patient with wildly invasive follicular carcinoma, who underwent surgery at another hospital and visited our hospital due to nodal metastasis, was enrolled in this study. 
Table I. Summary of nine follicular carcinomas with nodal metastasis.

\begin{tabular}{|c|c|c|c|c|c|c|c|c|c|c|c|c|}
\hline Case & $\begin{array}{l}\text { Age/ } \\
\text { Gender }\end{array}$ & Site & $\begin{array}{l}\text { Size } \\
(\mathrm{mm})\end{array}$ & Type & $\begin{array}{l}\text { Capsular } \\
\text { invasion }\end{array}$ & $\begin{array}{l}\text { Vascular } \\
\text { invasion }\end{array}$ & Necrosis & $\begin{array}{c}\text { Initial } \\
\text { operation }\end{array}$ & $\begin{array}{c}\text { Metastasis } \\
\text { at } \\
\text { presentation }\end{array}$ & $\begin{array}{l}\text { Metastasis } \\
\text { during } \\
\text { follow-up } \\
\text { (years) }\end{array}$ & $\begin{array}{c}\text { Follow-up } \\
\text { period } \\
\text { (months) }\end{array}$ & $\begin{array}{l}\text { Out- } \\
\text { come }\end{array}$ \\
\hline 1 & $33 / \mathrm{F}$ & lt & 25 & Minimally & + & - & - & NTT, C & lt $\mathrm{CN}$ & & 132 & Alive \\
\hline 2 & $40 / F$ & lt & 10 & Minimally & + & + & - & Lo & & $\begin{array}{l}\text { lt LN, Bone } \\
(7,10)\end{array}$ & 227 & Alive \\
\hline 3 & $15 / \mathrm{M}$ & lt & 86 & Minimally & - & + & - & Lo & & $\begin{array}{l}\text { rt CN, rt LN, } \\
\text { lt LN (2) }\end{array}$ & 90 & Alive \\
\hline 4 & $26 / F$ & $\mathrm{rt}$ & 30 & Minimally & + & - & - & Lo & & rt CN, lt CN (7) & 45 & Alive \\
\hline 5 & $69 / \mathrm{F}$ & lt & 22 & Widely & + & + & - & ST, C & lt $\mathrm{CN}$ & & 89 & Alive \\
\hline 6 & $60 / \mathrm{F}$ & lt & 58 & Widely & + & + & + & TT, C & lt $\mathrm{CN}$ & & 98 & Alive \\
\hline 7 & $32 / \mathrm{M}$ & $\mathrm{rt}$ & 90 & Widely & + & + & - & ST, C and L & $\mathrm{rt} \mathrm{CN}$ & rt LN ( 2 ) & 62 & Alive \\
\hline 8 & $21 / \mathrm{F}$ & $\mathrm{rt}$ & 50 & Widely & + & + & + & Lo & & $\begin{array}{c}\text { rt CN, rt LN, } \\
\text { lt CN, lt LN (6) }\end{array}$ & 173 & Alive \\
\hline 9 & $18 / \mathrm{F}$ & lt & 48 & Widely & + & + & - & Lo & & lt LN (3) & 56 & Alive \\
\hline
\end{tabular}

NTT, near total thyroidectomy; ST, subtotal thyroidectomy; Lo, lobectomy; C, central node dissection; C and L, central and lateral node dissection; CN, central node; LN, lateral node; lt, left lobe; rt, right lobe.

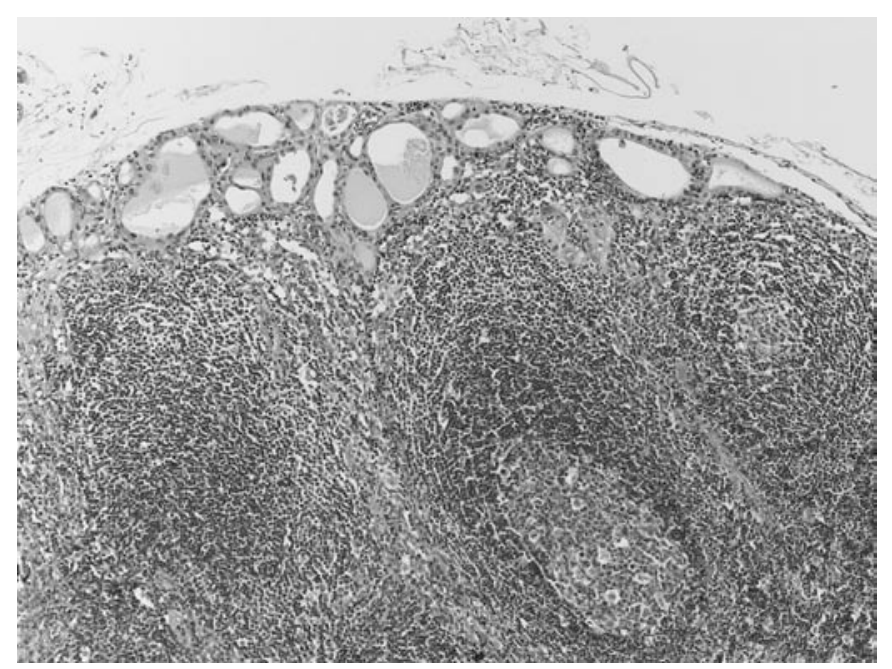

Figure 1. Nodal metastasis of follicular carcinoma found at the initial surgery. The lesion is small and located in the subcapsular area of the central lymph nodes.

Pathological diagnosis. Pathological diagnosis followed the new WHO classification (1). The follicular carcinoma was defined as follicular carcinoma showing vascular invasion, capsular invasion and/or metastasis and lacking the diagnostic nuclear characteristics of papillary carcinoma. PD-FC was not included in follicular carcinomas. The follicular carcinomas were divided into minimally invasive and widely invasive. Minimally invasive follicular carcinoma showed limited capsular and/or vascular invasion. This included a tumor that was diagnosed as a follicular adenoma and showed metastasis following surgery. Widely invasive follicular carcinoma showed the widespread infiltration of adjacent thyroid tissue and/or blood vessels.

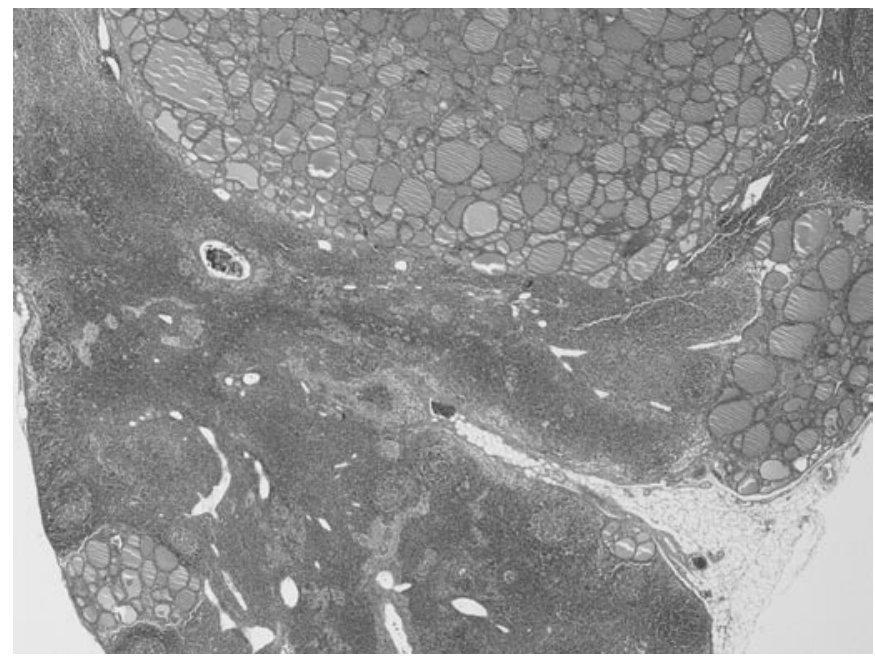

Figure 2. Nodal metastasis of follicular carcinoma found during the follow-up. Multiple lesions exist, extensively occupying the lateral lymph nodes.

\section{Results}

Of the 249 follicular carcinoma cases, $9(3.6 \%)$ revealed nodal metastasis (Table I). Of the 9 cases, 7 patients were female and 2 were male. Ages ranged from 15 to 69 years (average 34.9). The primary lesions were located in the left lobe in 6 cases and in the right lobe in 3 . A total of 4 cases were minimally invasive and the remaining 5 were widely invasive. The incidences of nodal metastasis in minimally invasive and widely invasive follicular carcinomas were 2.0 (4/198) and $9.8 \%(5 / 51)$, respectively. Cases $1,5,6$ and 7 received total, subtotal or nearly total thyroidectomy with a central node dissection. Nodal metastasis was unexpectedly observed 
during the initial surgery, and was ipsilateral. No recurrence or metastasis was noted in 3 patients (cases 1,5 and 6) during the follow-up period. The remaining case (case 7) underwent an ipsilateral lymphadenectomy 5 years after the initial operation due to extensive cervical nodal metastasis. A total of 5 patients (cases 2, 3, 4, 8 and 9) received only a lobectomy and presented with nodal metastasis 2-10 years after the initial operation. The patients were relatively younger than those with nodal metastasis following the initial operation. Nodal metastases in cases 3, 4 and 8 were bilateral and large. The largest dimensions of the primary carcinomas ranged from 10 to $90 \mathrm{~mm}$ (average $46.6 \mathrm{~mm}$ ), and were not related to age, gender, histological subgroup or state of nodal metastasis. During the follow-up period, distant metastasis to the bone was noted in case 2 . No patients succumbed to carcinoma.

Histologically, all primary tumors were completely or mostly encapsulated by thick fibrous connective tissue. The tumor cells proliferated in a microfollicular and/or trabecular manner. In cases 3 and 8, a medium-sized follicular pattern was also observed. There was no evidence of nuclear features indicating papillary carcinoma, including intracytoplasmic inclusions, ground glass nuclei and nuclear grooves. Necrosis was observed in cases 6 and 8. Capsular invasion was observed except in one minimally invasive case (case 3 ). Vascular invasion was observed except in cases 1 and 4 . Nodal metastatic lesions found during the initial surgery were small and located in the subcapsular area of the central lymph nodes (Fig. 1). On the other hand, the lesions found during the follow-up period were multiple and extensively occupied the lateral lymph nodes (Fig. 2). Immunohistochemically, Ki-67 (MIB-1; Dako, 1:200 dilution) labeling indices were $<1 \%$ in both primary and metastatic lesions.

\section{Discussion}

According to previous diagnostic criteria, follicular carcinoma of the thyroid included both WD-FC and PD-FC. However, in the current WHO classification, PD-FC is excluded from follicular carcinoma and is included in poorly differentiated carcinoma (1). Therefore, follicular carcinoma means only WD-FC. The distinction between WD-FC and PD-FC is difficult to determine (11-14). Follicular variants of papillary carcinoma have also been confused with follicular adenoma and/or carcinoma $(15,16)$. Our cases previously diagnosed as follicular carcinoma included various other lesions, such as papillary carcinoma, poorly differentiated carcinoma, follicular adenoma and adenomatous nodule. Such cases indicate that we should strictly exclude PD-FC and follicular variants of papillary carcinoma to study follicular carcinoma.

The incidences of nodal metastasis in follicular carcinomas are variable. They have been estimated to be from 4.7 up to $30.0 \%$ (3-8). In our study, $3.6 \%$ of follicular carcinomas revealed nodal metastasis. This incidence was lower than in previous studies. Nodal metastasis in the widely invasive type was more common than in the minimally invasive type, 9.8 and $2.0 \%$, respectively, and the incidences were also lower than those described in the textbook (10).

The number of minimally and widely invasive cases may comprise the main difference. If not, follicular variants of papillary carcinomas, which are more frequently associated with nodal metastasis and may be diagnosed as follicular carcinomas, may be included. Additionally, PD-FC, the incidence of nodal metastasis which is higher than WD-FC $(17,18)$, is included in previous studies. Therefore, we hypothesize that the incidence of nodal metastasis in follicular carcinomas based on the current classification should be lower than that reported in the analysis.

Microscopically, early lesions of nodal metastasis are found as small foci in the subcapsular areas of the lymph nodes (19), where a marginal sinus connecting with afferent lymphatic vessels is present. When extensive metastasis occurs, the lesions show multiple large nodules throughout the lymph nodes or completely occupy the lymph nodes. Our study showed that metastatic lesions of follicular carcinomas found at the time of the initial operation showed subcapsular small foci. The lesions were not clinically apparent, and it took 2-10 years for them to substantially occupy a number of lymph nodes. Primary lesions of follicular carcinomas with nodal metastasis were microscopically conventional. We failed to detect findings predicting the possibility of nodal metastasis. Additionally, no microscopic differences were noted between cases with nodal metastasis at the initial presentation or follow-up.

We did not identify any clinical clues indicating the nodal metastasis of follicular carcinoma. In our study, 6 out of 9 patients showed ipsilateral nodal metastasis. Notably, the remaining three patients with bilateral and extensive nodal metastases were young $(15,21$ and 26 years). Younger individuals may therefore exhibit a greater risk factor of extensive contralateral nodal metastasis. Generally, age is an important prognostic factor and the prognosis of patients below the age of 40 years is excellent $(2,17,20)$. Our findings, contradictory to this description, are noteworthy.

The prognostic importance of regional lymph node metastases is a controversial issue. Investigators have reported that the presence of this type of metastasis has no impact on recurrence or survival $(5,9,20)$. On the other hand, nodal metastasis is a risk factor for local or distant metastasis and cancer-specific mortality $(2,3,7)$. Our results showed that where no patients succumbed to the carcinoma, the presence of nodal metastasis did not affect the long-term outcome of follicular carcinoma.

\section{References}

1. DeLellis RA, Lloyd RV, Heitz PU and Eng C (eds): WHO Classification of Tumours, Pathology and Genetics of Tumours of Endocrine Organs. IARC Press, Lyon, pp67-72, 2004.

2. Crile G Jr, Pontius KI and Hawk WA: Factors influencing the survival of patients with follicular carcinoma of the thyroid gland. Surg Gynecol Obstet 160: 409-413, 1985.

3. Witte J, Goretzki PE, Dieken J, Simon D and Roher HD: Importance of lymph node metastases in follicular thyroid cancer. World J Surg 26: 1017-1022, 2002.

4. Lin JD, Liou MJ, Chao TC, Weng HF and Ho YS: Prognostic variables of papillary and follicular thyroid carcinoma patients with lymph node metastases and without distant metastases. Endocr Relat Cancer 6: 109-115, 1999.

5. Shaha AR, Loree TR and Shah JP: Prognostic factors and risk group analysis in follicular carcinoma of the thyroid. Surgery 118: 1131-1136, 1995.

6. Shaha AR, Shah JP and Loree TR: Patterns of nodal and distant metastasis based on histologic varieties in differentiated carcinoma of the thyroid. Am J Surg 172: 692-694, 1996.

7. Segal K, Arad A, Lubin E, Shpitzer T, Hadar T and Feinmesser R: Follicular carcinoma of the thyroid. Head Neck 16: 533-538, 1994. 
8. Chow SM, Law SC, Au SK, Leung TW, Chan PT, Mendenhall WM and Lau WH: Differentiated thyroid carcinoma: comparison between papillary and follicular carcinoma in a single institute. Head Neck 24: 670-677, 2002.

9. Hughes CJ, Shaha AR, Shah JP and Loree TR: Impact of lymph node metastasis in differentiated carcinoma of the thyroid: a matched-pair analysis. Head Neck 18: 127-132, 1996.

10. Ghossein R: Problems and controversies in the histopathology of thyroid carcinomas of follicular cell origin. Arch Pathol Lab Med 133: 683-691, 2009.

11. Suster S: Thyroid tumors with a follicular growth pattern, problems in differential diagnosis. Arch Pathol Lab Med 130: 984-988, 2006

12. Asa SL: The role of immunohistochemical markers in the diagnosis of follicular-patterned lesions of the thyroid. Endocr Pathol 16: 295-309, 2005.

13. Fletcher CDM (ed): Diagnostic Histopathology of Tumors. 2nd edition. Churchill Livingstone, London, pp979-993, 2000.

14. Rezk S and Khan A: Role of immunohistochemistry in the diagnosis and progression of follicular epithelium-derived thyroid carcinoma. Appl Immunohistochem Mol Morphol 13: 256-264, 2005.

15. Sakamoto A: Definition of poorly differentiated carcinoma of the thyroid: the Japanese experience. Endocr Pathol 15: 307-311, 2004 .
16. Albores-Saavedra $\mathrm{J}$ and Carrick $\mathrm{K}$ : Where to set the threshold between well differentiated and poorly differentiated follicular carcinomas of the thyroid. Endocr Pathol 15: 297-305, 2004.

17. Rosai J: Poorly differentiated thyroid carcinoma, introduction to the issue, its landmarks, and clinical impact. Endocr Pathol 15: 293-296, 2004.

18. Lang W, Choritz $\mathrm{H}$ and Hundeshagen $\mathrm{H}$ : Risk factors in follicular thyroid carcinomas. A retrospective follow-up study covering a 14-year period with emphasis on morphological findings. Am J Surg Pathol 10: 246-255, 1986.

19. Pilotti S, Collini P, Mariani L, Placucci M, Bongarzone I, Vigneri P, Cipriani S, Falcetta F, Miceli R, Pierotti MA and Rilke F: Insular carcinoma, a distinct de novo entity among follicular carcinomas of the thyroid gland. Am J Surg Pathol 21: 1466-1473, 1997

20. Natsugoe S, Aiko T and Shimazu H: A detailed histological study on occult metastasis of the lymph nodes. Jpn J Surg 21: 528-532, 1991.

21. Rao RS, Parikh HK, Deshmane VH, Parikh DM, Shrikhande SS and Havaldar R: Prognostic factors in follicular carcinoma of the thyroid, a study of 198 cases. Head Neck 18: 118-124, 1996. 